\title{
Effects of fertilization and submersion on morphological changes and production of two rice varieties with submersion stress conditions
}

\author{
Gribaldi $^{1,{ }^{*}}$, Nurlaili $^{1}$, and Supli Effendi Rahim ${ }^{2}$ \\ ${ }^{1}$ Agrotechnology Study Program Faculty of Agriculture, University of Baturaja, Jl. RatuPenghulu \\ No. 02301 Karang Sari Baturaja 32115, South Sumatra, Indonesia. \\ ${ }^{2}$ Agrotechnology Study Program Faculty of Agriculture, University of Palembang, J1. Dharmapala \\ No. 1A, Bukit Lama, Palembang City 30139, South Sumatra, Indonesia.
}

\begin{abstract}
This study aimed at studying the effects fertilization and submersion on morphological changes and production of two rice varieties with submersion stress conditions. The experimental design used in this research was randomized block design with three replications. The first factor is: Varieties $(\mathrm{V})$ : IR $64\left(\mathrm{~V}_{1}\right)$, Inpara $5\left(\mathrm{~V}_{2}\right)$. The second factor is the treatment $(\mathrm{P}): \mathrm{P}_{0}=$ Without submersion, $\mathrm{P}_{1}=$ Submersion 7-14 dap and fertilizer $\mathrm{N}, \mathrm{P}$ and $\mathrm{K} 7$ days after being submerged, $\mathrm{P}_{2}=$ Submersion 7-14 dap and fertilizer N, P and $\mathrm{K}+$ PPC Micro 7 days after being submerged $\mathrm{P}_{3}=$ Submersion 7-14 dap and 28-35 dap and fertilization N, P and $\mathrm{K} 7$ days after the first submersion, $\mathrm{P}_{4}=$ submersion 7-14 dap and 28-35 dap and fertilization N, P and K + PPC Micro 7 days after the first submersion. Results of the study showed the fertilization treatment after being submerged affected the morphological changes of rice crop with submersion stress conditions. Treatment of the fertilization $\mathrm{N}, \mathrm{P}$ and $\mathrm{K}+$ PPC Micro 7 days after the first submersion give the best effect on the growth and yield of rice under submergence stress conditions.
\end{abstract}

\section{Introduction}

Submerged rice plants result in reduced oxygen supply. According to [1], the diffusion of oxygen in the water $10^{4}$ times slower than in the air. This decrease in gas diffusion results in poor growth, metabolism, and tolerance of plants [5]. [1] revealed that the roots of oxygen deficient environment greatly inhibit ion uptake by roots and ion transport to the header, so the concentration of nutrients like N, P and $\mathrm{K}$ in leaves decreased. In addition the plant is submerged under stress shortly after being submerged. For subsequent metabolic processes and internal repair plant, required the availability of sufficient carbohydrate reserves once submerged. Efforts can be made to promote tolerance and availability of plant nutrients after being submerged can be through the fertilization treatment after being submerged. The results of the research in rice conducted by [2] states that, fertilization after the stress submerged conducted one week after the completion of submerged stress

Corresponding author: gribaldi64@yahoo.co.id 
and fertilizers are given around 30-50 kg N, 20-30 kg of P2 O5 and $20-30 \mathrm{~kg} \mathrm{~K}$ ha-1 can speed up the recovery of rice plants.

Recovery after being submerged require sufficient nutrients and can be quickly absorbed by plants. Fertilization through leaves is the additions and improvements fertilization through the soil or roots in certain circumstances where the absorption of the roots of the important elements is reduced. One effort to overcome the problem by granting Complementary Liquid Fertilizer (PPC) as an additional micro nutrients Si and Zn through the leaves, with a recommended dosage for the paddy crop is $2 \mathrm{cc} / 1$ of water. Furthermore [6] states that giving treatment "Plant Phytoregulator" and Nitrogen can help rice plants speed recovery after being submerged. This study aimed at studying the effects fertilization and submersion on morphological changes and production of two rice varieties with submersion stress conditions.

\section{Materials and methods}

This experiment was conducted at the experimental garden plastic Faculty of Agriculture, University of Baturaja. This experiment used randomized block design arranged as factorial with two factors treatments and three replications. The experimental treatment consists of: The first factor is: Rice Varieties $(\mathrm{V})$ consists of: = IR 64 Variety $\left(\mathrm{V}_{1)}\right.$, Inpara 5 Variety $\left(\mathrm{V}_{2}\right)$. The second factor is the treatment $(\mathrm{P})$, comprising: $\mathrm{P}_{0}=$ Without submersion + basic fertilizer, $\mathrm{P}_{1}=$ Submersion 7-14 dap and fertilizer N, P and $\mathrm{K} 7$ days after being submerged, $\mathrm{P}_{2}=$ Submersion 7-14 dap and fertilizer N, P and $\mathrm{K}+$ PPC Micro 7 days after being submerged $\mathrm{P}_{3}=$ submersion 7-14 dap and 28-35 dap and fertilizer $\mathrm{N}, \mathrm{P}$ and $\mathrm{K} 7$ days after the first submersion, $\mathrm{P}_{4}=$ submersion 7-14 dap and 28-35 dap and $\mathrm{N}, \mathrm{P}$ and $\mathrm{K}+\mathrm{PPC}$ Micro 7 days after the first submersion.

Seed of Inpara 5 and IR 64 varieties were incubated for 3 days, after germinating seedling in a medium plastic tub with length of $40 \mathrm{~cm}$, width $30 \mathrm{~cm}$ and in $13 \mathrm{~cm}$ were filled valley marshland as much as $15 \mathrm{~kg}$, in which the soil previously treated for $\mathrm{N}, \mathrm{P}, \mathrm{K}$, $\mathrm{Si}$ and $\mathrm{Zn}$, and manure, each with a dose of 60, 40, 40, 30 and $20 \mathrm{~kg}$ ha-1 and 10 ton ha-1 [7]. Seeds that have been aged 21 days in seedbed tubs lifted and planted three seedlings of rice plants into each black polybag filled valley marshlands each $5 \mathrm{~kg}$ and has flooded approximately 30 days. Submersion treatment tailored to each treatment, for treatment of $P_{1}$ and $\mathrm{P}_{2}$ 7-14 submerged dap and for the treatment $\mathrm{P}_{3}$ and $\mathrm{P}_{4}$ submerged 7-14 dap and 28-35 dap 7 days. High water depth of at least $15 \mathrm{~cm}$ from the surface of the plant.

Basic fertilization (Urea 100, SP36 128 and $\mathrm{KCl} 100$ (kg ha-1)) is performed at the time of planting and fertilizing once submerged done 21 days after planting with fertilizer dose used is for fertilizer N, P2O5, K2O each with a dose of 50,30,30 (kg ha-1) as well as micro PPC $2 \mathrm{ml} / 1$ of water. PPC fertilizer application of micro-interval of 7 days until the phase of primordia, whereas inorganic fertilizers administration by means embedded into the ground as deep as $10 \mathrm{~cm}$.

Observations conducted in this study included: 1) plant height $(\mathrm{cm}), 2)$ The number of tillers (tillers), 3) dry weight of plants (g), 4) The ratio of root / shoot, 5) Age flowering (day), 6) Grain yields per clump, and (g), 7) Weight of 100 grains (g).

This experiment was conducted at the experimental garden plastic Faculty of Agriculture, University of Baturaja. This experiment used randomized block design arranged as factorial with two factors treatments and three replications. The experimental treatment consists of: The first factor is: Rice Varieties (V) consists of: = IR 64 Variety (V1), Inpara 5 Variety (V2). The second factor is the treatment $(\mathrm{P})$, comprising: $\mathrm{P} 0=$ Without submersion + basic fertilizer, P1 = Submersion 7-14 hst and fertilizer N, P and K 7 days after being submerged, $\mathrm{P} 2=$ Submersion 7-14 hst and fertilizer N, P and $\mathrm{K}+$ PPC Micro 7 days after being submerged $\mathrm{P} 3=$ submersion 7-14 hst and 28-35 hst and fertilizer N, P and $\mathrm{K} 7$ days after 
the first submersion, $\mathrm{P} 4=$ submersion 7-14 hst and 28-35 hst and N, P and $\mathrm{K}+\mathrm{PPC}$ Micro 7 days after the first submersion.

Seed of Inpara 5 and IR 64 varieties were incubated for 3 days, after germinating seedling in a medium plastic tub with length of $40 \mathrm{~cm}$, width $30 \mathrm{~cm}$ and in $13 \mathrm{~cm}$ were filled valley marshland as much as $15 \mathrm{~kg}$, in which the soil previously treated for $\mathrm{N}, \mathrm{P}, \mathrm{K}$, Si and Zn, and manure, each with a dose of 60, 40, 40, 30 and $20 \mathrm{~kg}$ ha-1 and 10 ton ha-1 (Suwignyo et al., 2012). Seeds that have been aged 21 days in seedbed tubs lifted and planted three seedlings of rice plants into each black polybag filled valley marshlands each $5 \mathrm{~kg}$ and has flooded approximately 30 days. Submersion treatment tailored to each treatment, for treatment of P1 and P2 7-14 submerged hst and for the treatment P3 and P4 submerged 7-14 hst and 28-35 hst 7 days. High water depth of at least $15 \mathrm{~cm}$ from the surface of the plant.

Basic fertilization (Urea 100, SP36 128 and $\mathrm{KCl} 100$ (kg ha-1)) is performed at the time of planting and fertilizing once submerged done 21 days after planting with fertilizer dose used is for fertilizer N, P2O5, K2O each with a dose of 50, 30, 30 (kg ha-1) as well as micro PPC $2 \mathrm{ml} / 1$ of water. PPC fertilizer application of micro-interval of 7 days until the phase of primordia, whereas inorganic fertilizers administration by means embedded into the ground as deep as $10 \mathrm{~cm}$. Observations included: 1) plant height (cm), 2) The number of tillers (tillers), 3) dry weight of plants (g), 4) The ratio of root / shoot, 5) Age flowering (day), 6) Grain yields per clump ( g), 7) Weight of 100 grains (g).

\section{Result and discussion}

\subsection{Result}

Results of variance analysis in Table 1 showed that for every parameter between varieties affect no significant effect unless the number of productive tillers while between fertilization treatments significantly affect except grain weight of 100 grains. The interaction between varieties and fertilizer treatment effect is not obvious unless the dry weight of the plant.

Table 1. Results of variance analysis influence fertilization treatment after being submerged in both rice varieties for all the observed variables.

\begin{tabular}{|c|l|c|c|c|}
\hline No & \multicolumn{1}{|c|}{ Observed parameters } & Variety & Fertilization & Interactions \\
\hline 1 & Percentage of survived plant & $\mathrm{Ns}$ & $*$ & $\mathrm{Ns}$ \\
\hline 2 & Plant height & $\mathrm{Ns}$ & $*$ & $\mathrm{Ns}$ \\
\hline 3 & The number of productive tillers/plant & $*$ & $*$ & $\mathrm{Ns}$ \\
\hline 4 & Plant dry matter weight & $\mathrm{Ns}$ & $*$ & $*$ \\
\hline 5 & Percentage of filled grains per panicle & $\mathrm{Ns}$ & $*$ & $\mathrm{Ns}$ \\
\hline 6 & Number of grains per panicle & $\mathrm{Ns}$ & $*$ & $\mathrm{Ns}$ \\
\hline 7 & 100 grains weight & $\mathrm{Ns}$ & $\mathrm{Ns}$ & $\mathrm{Ns}$ \\
\hline 8 & Grain yield per clump & $\mathrm{Ns}$ & $*$ & $\mathrm{Ns}$ \\
\hline
\end{tabular}

Notes: $*$ = significant effect

Ns = no significant effect

\subsubsection{Percentage of survived plant}

F test results showed fertilization treatment give significant effect, but the varieties of interaction affect no significant effect on the percentage of survived plants. The percentage of plants in the twice submersion $\left(\mathrm{P}_{3}\right.$ and $\left.\mathrm{P}_{4}\right)$ tend to be lower than those experienced once 
submersion $\left(\mathrm{P}_{1}\right.$ and $\left.\mathrm{P}_{2}\right)$, at various fertilization treatment for all varieties tested (Table 2). In the twice submersion conditions, Inpara 5 varieties have live plants percentage higher than IR 64 varieties at various fertilization treatment, which amounted to 50 percent. While the provision of fertilizer N, P and $\mathrm{K}+$ PPC Micro 7 days after the first submersion $\left(\mathrm{P}_{4}\right)$ on IR 64 varieties tend to be higher than the percentage of plants $\mathrm{P}_{3}$ fertilization, which is 45.83 percent, an increase of 22.2 percent.

Table 2. Effect of fertilization after being submerged in both rice varieties on the percentage of survived plants stress submersion conditions in turbidwater.

\begin{tabular}{|c|c|c|c|c|c|}
\hline Treatment & $\mathrm{P}_{0}$ & $\mathrm{P}_{1}$ & $\mathrm{P}_{2}$ & $\mathrm{P}_{3}$ & $\mathrm{P}_{4}$ \\
\hline IR 64 & 100.00 & 100.00 & 100.00 & 37.50 & 45.83 \\
\hline Inpara 5 & 100.00 & 100.00 & 100.00 & 50.00 & 50.00 \\
\hline
\end{tabular}

Notes: $\quad \mathbf{P}_{\mathbf{0}}=$ Without submersion + basic fertilizer, $\mathbf{P}_{\mathbf{1}}=$ Submersion of 7-14 dap and fertilizer N, P and $\mathrm{K} 7$ days after being submerged, $\mathbf{P}_{\mathbf{2}}=$ Submersion of 7-14 dap and fertilizer N, P and $\mathrm{K}$ + PPC Micro 7 days after being submerged $\mathbf{P}_{\mathbf{3}}=$ submersion of 7-14 and 28-35 dap and fertilizer N, P and K 7 days after the first submersion, $\mathbf{P}_{\mathbf{4}}=$ submersion of 7-14 dap and 2835 dap and fertilizer N, P and K + PPC Micro 7 days after the first submersion.

\subsubsection{Plant height}

F test results showed significant effect on fertilization treatment, but the varieties of interaction affect no significant effect on plant height. Higher plants by the twice submersion $\left(\mathrm{P}_{3}\right.$ and $\left.\mathrm{P}_{4}\right)$ tend to be lower than that experienced once submersion $\left(\mathrm{P}_{1}\right.$ and $\left.\mathrm{P}_{2}\right)$, at various fertilization treatment for all varieties tested (Table 3). IR 64 varieties treated with $\mathrm{N}, \mathrm{P}, \mathrm{K}+\mathrm{PPC}$ micro 7 days after being submerged $\left(\mathrm{P}_{2}\right)$ tend to have the highest plant which the height is $112.17 \mathrm{~cm}$.

Table 3. Effect of fertilization after being submerged in both rice varieties to the height of plant $(\mathrm{cm})$ stress submersion conditions in turbidwater.

\begin{tabular}{|c|c|c|c|c|c|}
\hline Treatment & $\mathrm{P}_{0}$ & $\mathrm{P}_{1}$ & $\mathrm{P}_{2}$ & $\mathrm{P}_{3}$ & $\mathrm{P}_{4}$ \\
\hline IR64 & 106.02 & 108.83 & 112.17 & 70.50 & 78.67 \\
\hline Inpara 5 & 114.00 & 101.95 & 110.17 & 81.50 & 86.12 \\
\hline
\end{tabular}

Notes : $\mathrm{P}_{0}=$ Without submersion + basic fertilizer, $\mathrm{P}_{1}=$ Submersion 7-14 dap and fertilizer $\mathrm{N}, \mathrm{P}$ and $\mathrm{K} 7$ days after being submerged, $\mathrm{P}_{2}=$ Submersion 7-14 dap and fertilizer $\mathrm{N}, \mathrm{P}$ and $\mathrm{K}+\mathrm{PPC}$ Micro 7 days after being submerged $\mathrm{P} 3=$ submersion 7-14 dap and 28-35 dap and fertilizer $\mathrm{N}, \mathrm{P}$ and $\mathrm{K} 7$ days after the first submersion, $\mathrm{P} 4=$ submersion 7-14 dap and 28-35 dap and $\mathrm{N}$, $\mathrm{P}$ and $\mathrm{K}+\mathrm{PPC}$ Micro 7 days after the first submersion.

\subsubsection{The number of productive tillers per plant}

F test results showed fertilization treatment and varieties give significant effect, but the interaction effect was not significant on the number of productive tillers. The provision of fertilizer treatment on varieties undergo twice submersion ( $\mathrm{P} 3$ and $\left.\mathrm{P}_{4}\right)$ inclined tiller number less than that experienced once submersion $\left(\mathrm{P}_{1}\right.$ and $\left.\mathrm{P}_{2}\right)$ (Fig. 1). Inpara 5 varieties which given various treatments of N, P and K + PPC Micro 7 days after being submerged tend to have the highest number of productive tillers, which are 25.17 stem. 


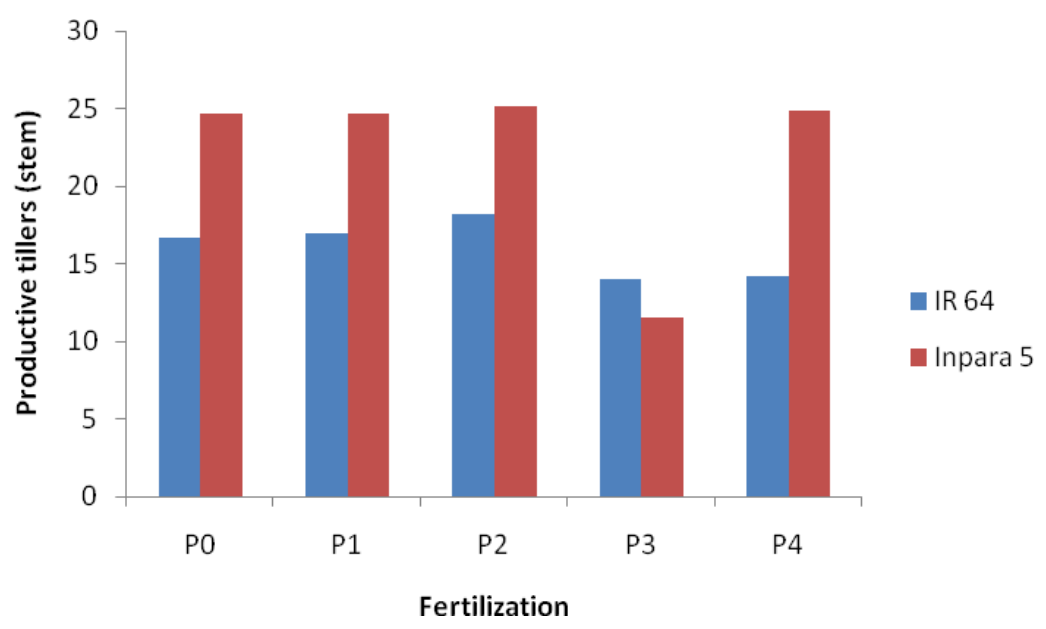

Fig. 1. Number of tillers 42 dap, on each of the varieties of rice and fertilizer treatment in a stress submerged conditions. $\mathbf{P}_{\mathbf{0}}=$ Without submersion + basic fertilizer, $\mathbf{P}_{\mathbf{1}}=$ Submersion 7-14 dap and fertilizer N, P and K 7 days after being submerged, $\mathbf{P}_{\mathbf{2}}=$ Submersion 7-14 dap and fertilizer N, P and $\mathrm{K}+$ PPC Micro 7 days after being submerged $\mathbf{P}_{\mathbf{3}}=$ submersion 7-14 dap and 28-35 dap and fertilizer $\mathrm{N}, \mathrm{P}$ and $\mathrm{K} 7$ days after the first submersion, $\mathbf{P}_{\mathbf{4}}=$ submersion 7-14 dap and 28-35 dap and fertilizer $\mathrm{N}, \mathrm{P}$ and $\mathrm{K}+\mathrm{PPC}$ Micro 7 days after the first submersion.

\subsubsection{Plant dry matter weight}

F test results showed varieties treatment give no significant effect, but fertilization and their interactions significantly affected on the plant dry matter weight. The provision of fertilizer treatment on varieties undergo twice submersion (P3 and P4) the dry matter weight of plants tend to be lower than the varieties experiencing once submersion (P1 and P2) (Fig. 2). IR 64 varieties treated fertilizer of N, P and K + PPC Micro 7 days after being submerged tend to have the highest plant dry matter weight, that is $63.1 \mathrm{~g} / \mathrm{clump}$ for once submersion, while at the twice submersion, Inpara 5 varieties given fertilization treatment for N, P and K + PPC Micro 7 days after being submerged tend to have the highest plant dry weight, which is $40.9 \mathrm{~g}$ / clump. 


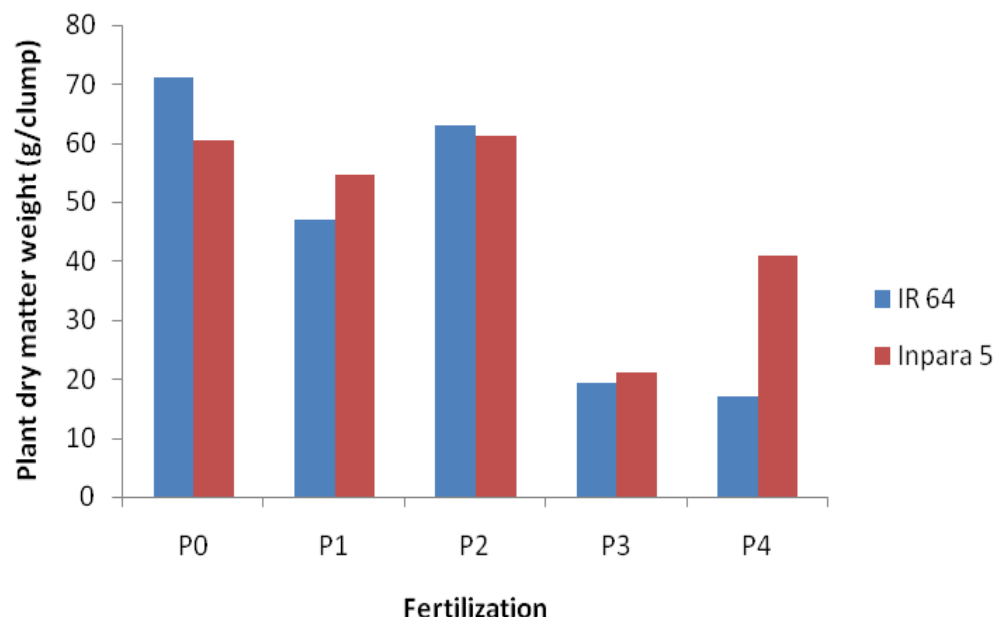

Fig. 2. The dry weight of the plant life of $42 \mathrm{dap}$, on each of the varieties of rice and fertilizer treatment in a stress submerged conditions. $\mathbf{P}_{\mathbf{0}}=$ Without submersion + basic fertilizer, $\mathbf{P}_{\mathbf{1}}=$ Submersion 7-14 dap and fertilizer N, P and K 7 days after being submerged, $\mathbf{P}_{\mathbf{2}}=$ Submersion 7-14 dap and fertilizer N, P and K + PPC Micro 7 days after being submerged $\mathbf{P}_{\mathbf{3}}=$ submersion 7-14 dap and 28-35 dap and fertilizer N, P and K 7 days after the first submersion, $\mathbf{P}_{\mathbf{4}}=$ submersion 7-14 dap and 28-35 dap and fertilizer N, P and K + PPC Micro 7 days after the first submersion.

\subsubsection{Yield and yield components}

F test results showed significant effect on fertilization treatment, but the variety and interaction give no significant effect on grain yield per clump.

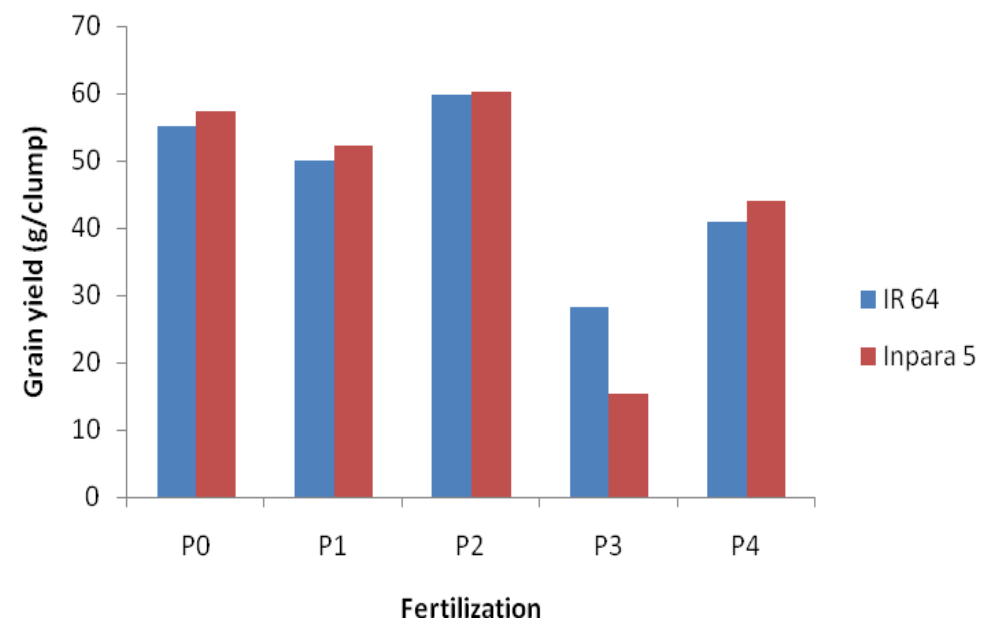

Fig. 3. Grain yields in each variety of rice and fertilizer treatment in a stress submerged conditions.

$\mathbf{P 0}=$ Without submersion + basic fertilizer, $\mathbf{P 1}=$ Submersion 7-14 hst and fertilizer N, P and K 7 days after being submerged, $\mathbf{P 2}=$ Submersion 7-14 hst and fertilizer N, P and $\mathrm{K}+\mathrm{PPC}$ Micro 7 days after being submerged $\mathbf{P 3}=$ submersion 7-14 hst and 28-35 hst and fertilizer N, P and $\mathrm{K} 7$ days after 
the first submersion, $\mathbf{P 4}=$ submersion 7-14 hst and 28-35 hst and fertilizer N, P and K + PPC Micro 7 days after the first submersion.

The provision of fertilizer treatment on varieties undergo twice submersion $\left(\mathrm{P}_{3}\right.$ and $\left.\mathrm{P}_{4}\right)$ grain yield per clump tended to belower than varieties which experience once submersion $\left(\mathrm{P}_{1}\right.$ and $\left.\mathrm{P}_{2}\right)$. Inpara 5 varieties and IR 64 were treated for $\mathrm{N}, \mathrm{P}, \mathrm{K}+\mathrm{PPC}$ micro 7 days after being submerged $\left(\mathrm{P}_{2}\right)$ tend to have the highest grain yield, 60.32 and $59.67 \mathrm{~g} / \mathrm{clump}$ and grain yield exceeded that did not experience submersion $\left(\mathrm{P}_{0}\right)$, that is 57.37 and $40.83 \mathrm{~g}$ per clump (Fig. 3).

Table 4. Effect of fertilization after being submerged in both rice varietiesto some components of the results of stress submersion conditions in the turbid water.

\begin{tabular}{|c|c|c|c|c|c|c|}
\hline \multirow{2}{*}{ Treatment } & \multicolumn{3}{|c|}{ Inpara 5 } & \multicolumn{3}{c|}{ IR64 } \\
\cline { 2 - 7 } & $\mathbf{1}$ & $\mathbf{2}$ & $\mathbf{3}$ & $\mathbf{1}$ & $\mathbf{2}$ & $\mathbf{3}$ \\
\hline P0 & 141.67 & 94.33 & 2.22 & 145.85 & 93.11 & 2.18 \\
\hline P1 & 153.67 & 94.91 & 2.24 & 140.67 & 91.94 & 2.22 \\
\hline P2 & 157.17 & 95.32 & 2.32 & 141.50 & 95.68 & 2.21 \\
\hline P3 & 117.00 & 84.06 & 2.20 & 117.50 & 81.59 & 2.19 \\
\hline P4 & 127.33 & 83.80 & 2.32 & 119.83 & 82.34 & 2.23 \\
\hline
\end{tabular}

Remarks: 1: The number of grains per panicle (grains), 2: Percentage of grain pithy (\%), 3: grain weight of 100 grains $(\mathrm{g})$. $\mathbf{P 0}=$ Without submersion + basic fertilizer, $\mathbf{P 1}=$ Submersion 7-14 hst and fertilizer N, P and K 7 days after being submerged, $\mathbf{P 2}=$ Submersion 7-14 hst and fertilizer N, P and $\mathrm{K}+\mathrm{PPC}$ Micro 7 days after being submerged P3 = submersion 7-14 hst and 28-35 hst and fertilizer $\mathrm{N}, \mathrm{P}$ and $\mathrm{K} 7$ days after the first submersion, $\mathbf{P 4}=$ submersion 7-14 hst and 28-35 hst and fertilizer N, $\mathrm{P}$ and $\mathrm{K}+\mathrm{PPC}$ Micro 7 days after the first submersion.

Yield components in both rice varieties tend to decrease in submersion twice compared with once submersion (Table 4). Treatment of N, P and K + PPC Micro 7 days after being submerged in both rice varietiesthe components of grain yield tend to be higher compared to other fertilizer treatment, even at Inpara5 varieties tend to be higher than without submergence at once submersion.

\section{Discussion}

Giving fertilization treatment after being submerged can improve the recovery of rice plants to stress submerged, it can be seen from the changes in plant height, number of tillers, plant dry weight and grain yield per clump that has a value approaching and even exceeding the changes in rice plants that are not submerged (P0), the ability of plants to quickly recover from stress submerged is very important. Plants that are tolerant with stress submerged are able not only to survive but also to grow back after reeling submerged. [3] research results mention that the recovery was good for rice crops experiencing stress submerged characterized by rapid out new tillers so that at the end of growth, the plant has a number of tillers almost same or even exceed compared with plants that do not undergo submersion.

Twice submersion treatment ( $\mathrm{P} 3$ and $\mathrm{P} 4)$ in both rice varieties showed a greater drop than once submersion (P1 and P2) on all the observed variables. This is due to the longer and the frequent the plant having a submerged condition, so the damage suffered by the plants is greater because the metabolism of plants is hampered by the lack of oxygen. According to [1] revealed that, the lack of oxygen greatly inhibit ion uptake by roots and ions transport to penetrate, so the concentration of N, P and $\mathrm{K}$ in leaves decreased. More [4] stated that the lack of oxygen due to gripped by submersionis a limiting factor of growth and productivity.

To increase crop productivity growth and recovery efforts are needed to the treatment of plant once gripped by submersion, through fertilization after being submerged in order that 
thenutrients neededby plants are enough and can be quickly absorbed by plants. The provision of combined fertilization through roots and leaves is one attempt to address these conditions. [6] states that the giving of treatment "Plant Phytoregulator" and Nitrogen can help rice plants speed the recovery after being submerged. The results of the research in rice conducted by [2] states that the provision of fertilizer after stress submerged conducted one week after the stress submerged completedand fertilizers is given around $30-50 \mathrm{~kg} \mathrm{~N}$, 20-30 kg P2O5 and 20-30 kg K2O ha- 1 can speed up the recovery of rice plants.

Giving fertilization treatment after being submerged with $\mathrm{N}, \mathrm{P}$ and $\mathrm{K}+\mathrm{PPC}$ micro 7 days after being submerged $\left(\mathrm{P}_{2}\right)$ is the best fertilizer treatment to improve recovery of rice plant, it is seen changes in almost all the observed variables. Inpara 5 varieties treated for $\mathrm{N}, \mathrm{P}$ and $\mathrm{K}+\mathrm{PPC}$ micro 7 days after being submerged $\left(\mathrm{P}_{2}\right)$ produces highgrain yield per clump, due to the growth of this variety is better than the otherfertilizer treatment, it can be seen from the changes in plant height, number of tillers, and plant dry weight. The dry weight of the high plant in P2 treatment is due to the high plant height and number of tillers that many lead to better plant growth so as to produce a high grain anyway.

\section{Conclusion}

Based on results and discussion in the study, it can be concluded that: (1) Fertilization after being submerged in both rice varieties were experiencing stress submersion in the turbid water affect the growth and production of rice, (2) Provision of fertilizer N, P and K + PPC Micro 7 days after being submerged best effect on the growth and production of rice, and (3) The longer the submersion of the rice variety, the greater the effect on growth and rice production.

We especially wish to acknowledge the Ministry of Research, Technology and Higher Education that had already provided funding for this research through Competitive Research Grant (Hibah Bersaing) for fiscal year of 2015-2016.

\section{References}

1. W. Armstrong, M.C. Drew, Plant roots: the hidden half 3, 729 (2002)

2. IRRI, The Research and Development Council of Food Crops, Submergence Tolerant Rice (Food Crops Research and Development Center, 2009)

3. A.K. Makarim, E. Suhartatik, G.R. Pratiwi, Ikhwani, Assembly of rice production technology on swamp land and flooding prone swamp (>15 days) for minimum productivity of 7 tha-1 (Indonesian Rice Research Institute, Indonesian Agricultural Research and Development, 2009)

4. R.K. Sairam, D. Kumutha, K. Ezhilmathi, Curr. Sci., 96, 674 (2009)

5. R.K. Sarkar, J.N. Reddy, S.G. Sharma, A.M. Ismail, Curr. Sci., 91, 899 (2006)

6. R.A Suwignyo, J. TanamanTropika., 8, 45 (2005)

7. R.A. Suwignyo, A. Wijaya, H. Sihombing, Gribaldi, J. Lahan Suboptimal., 1, 1 (2012) 